\title{
The Assessment of Integrated Functional Adult Education Program in Oromia Regional State, Ethiopia: Reflection on Practice
}

\author{
Habtamu Desalegn Gemechu ${ }^{1}$, Atakilt Hagos ${ }^{2}$, Geberew Tulu Mekonnen ${ }^{3,4, *}$ \\ ${ }^{1}$ Senior Researcher, Public Policy, Social and Legal Affair Research Institute, Oromia State University, Addis Ababa, Ethiopia \\ ${ }^{2}$ Ethiopian Management Institute, Addis Ababa, Ethiopia \\ ${ }^{3}$ College of Arts, Law, and Education, University of Tasmania, Launceston, Australia \\ ${ }^{4}$ College of Education and Behavioural Studies, Addis Ababa University, Addis Ababa, Ethiopia
}

Received December 23, 2020; Revised February 25, 2021; Accepted June 28, 2021

\section{Cite This Paper in the following Citation Styles}

(a): [1] Habtamu Desalegn Gemechu, Atakilt Hagos, Geberew Tulu Mekonnen, "The Assessment of Integrated Functional Adult Education Program in Oromia Regional State, Ethiopia: Reflection on Practice," Universal Journal of Educational Research, Vol. 9, No. 7, pp. 1472-1485, 2021. DOI: 10.13189/ujer.2021.090713.

(b): Habtamu Desalegn Gemechu, Atakilt Hagos, Geberew Tulu Mekonnen (2021). The Assessment of Integrated Functional Adult Education Program in Oromia Regional State, Ethiopia: Reflection on Practice. Universal Journal of Educational Research, 9(7), 1472-1485. DOI: 10.13189/ujer.2021.090713.

Copyright $\mathrm{C} 2021$ by authors, all rights reserved. Authors agree that this article remains permanently open access under the terms of the Creative Commons Attribution License 4.0 International License

\begin{abstract}
This study reports the status and challenges of the integrated functional adult literacy program's implementation in Ethiopia. It dealt explicitly with adult learners' participation, facilitators' motivation, and stakeholder collaboration. Little is known about functional adult literacy in Ethiopia [1]. Document analysis, focus group discussion, and questionnaire were used to collect the data. A total of 418 participants took part in the study. Descriptive (frequency and percentage) and inferential statistics (multiple regression model) were used to analyse the quantitative data whilst thematic analysis was used for qualitative part. The results showed that dropout rates and discontinuous program attendance were found to be the significant factors affecting those adult learners in the system. Lack of facilitators' motivation and weak stakeholder collaboration was also identified as impeding factors. The age of adult learners, their annual income, appropriateness of the program schedule, and adult learner occupation significantly determined adult learner program attendance. Based on the findings of the study, unless the program operation is collaboratively planned, resourced and monitored, it could be challenging to know whether the program is for the needy and up to the expected pace or not. So, effective monitoring and evaluation in program operation have its own stance to improve program implementation. The study suggests that consensus
\end{abstract}

building, frequent program monitoring, and program enforcement would be worth considering providing quality education for adult learners.

Keywords Integrated Functional Adult Education, Stakeholder Collaboration, Adult Learner Participation, Facilitators' Motivation

\section{Background}

Adult literacy is one of the growing concerns today that got special attention at the 1990 World Conference on Education for All (held in Jomittien, Thailand) [2, 3]. Rising adult literacy by the year 2000 was one of the worldwide goals of that conference $[4,5]$. This dramatically changed views on adult literacy and illiteracy from the 1990s onward. Most importantly, people's knowledge and ability to read and write made literacy one of the fundamental requirements of global economic growth and development $[6,7]$.

Being cognizant of the role of education in social, political and economic aspect and realising the access and quality problem of the previous education system, Ethiopia has formulated new education and training policy 
in 1994 [8]. Following the enactment of Ethiopia's 1994 education and training policy, functional adult literacy has been promoted in education sectors development programs such as ESDP I, ESDP II, ESDP III and ESDP IV so as to transform the whole community $[1,9,10]$. Especially in ESDP IV [10], it was recognised that the high levels of illiteracy in the adult population in Ethiopia were a barrier to achieve its development goals [11].

Different government reports $[1,12,13]$ and strategic document [14] show that the Ethiopian government has officially endorsed integrated functional adult education a priority in 2008. Those documents justified that the general objective of national adult education strategy is to establish an integrated approach for adult education system to provide quality and relevant learning programs for youth and adults that enable them to participate in development aspects.

With these issues under consideration, the integrated functional adult education program is being implemented all over the country $[11,14]$; Jidda district, the researcher's study area, is one of Oromia region in which the IFAE program has been on implementation.

Although there was a move toward implementing the adult literacy program, national reports [1, 12, 13] and some local studies showed that the program was not implemented as it was expected in Ethiopia. Those investigations examined the program execution and effectiveness from different dimensions. For instance, researchers $[6,15,16]$ indicated that adult education was not well implemented in Ethiopia. Nevertheless, methodologically those studies were not explanatory. Thus, the researchers used descriptive and explanatory research type to assess the program implementation critically.

\section{Context of the Study}

According to UNESCO education for all global monitoring report [17], adult literacy has not improved yet globally. The report showed that about 743 million adults were still illiterate most likely living in developing countries. Of these illiterates, women accounted for two-thirds of the illiterates.

Evidencing UNESCO Institute for Statistics (18), EFA Global Monitoring Report, the Ethiopian Ministry of Education ESDP IV action plan [11] indicated the adult national illiteracy rate was $64 \%$ (male $50 \%$, female $77 \%$ ) in which there were 23,270,767 illiterate adults. Among these, 8,992,983 were males and 14,277,784 were females (p.12). Similarly, the education statistics annual abstract of the Ministry of Education [1]) also showed that even though enrollment in functional adult literacy was targeted to be 18.2 million adults in $2013 / 14$, the achievement was only 6.5 million. This is found to be slightly higher than the figure for 2009/10, which was 5.2 million.

The GTP I report of Ethiopia [12] and empirical studies
$[6,15,16]$ in a different corner of the country also asserted that the program was not implemented at the expected pace. The factors that adversely affected the implementation of the program were: lack of community awareness and negative attitude towards the program [16]; inadequate provision of instructional material; low financial expenditure on the program; and, insufficient monitoring and supervision $[6,15,16]$.

Though the organisation and implementation of IFAEP are local-based, previous local research assessed the program implementation and its challenges from different perspectives. However, the reason behind those challenges mainly related to stakeholder collaboration, adult education facilitator selection and their motivation, and adult learners' participation were not addressed well.

Furthermore, the IFAEP implementation was assessed only by few researchers as per it is newly emerged action and problem-oriented education system [1]. Little is known about IFAEP implementation from the perspectives of stakeholder collaboration, adult education facilitators' selection and motivation and adult learners' participation [6]. In addition, this study was different methodologically from the previous research by using a mixed-method approach to explore the participants' lived experience about program implementation. Therefore, investigating the determinant factors impeding adult learners' involvement in the program was essential and timely. The study is designed to address the following research questions.

\section{Research Questions}

1) What is the current implementation status of integrated functional adult education program (IFAEP) in relation to stakeholder collaboration, facilitators' motivation and adult learners' participation in Jidda district of Oromia Regional State?

2) What are the challenges to the IFAEP implementation with regard to stakeholder collaboration, facilitators' motivation and adult learners' participation?

3) What are the factors that influence adult learners' participation in the IFAEP?

\section{Methodology}

\section{Study Area}

This research was conducted in Jidda, one of the districts in North Shoa in Oromia Regional State, in Ethiopia where IFAEP is on execution. From researchers' experience and practical observation, the IAEP was poorly implemented in the district. Moreover, [19] report also showed that IAEP was not operated to the desired level in the study area. Though the program was in execution 
across the region, the district is purposively selected as per it was independently structured lately after other districts in North shoa.

\section{Research Design}

This research followed the mixed research approach. This approach is selected as an appropriate design to explore the on-going process and trends that are useful for a better understanding of research problems than using either quantitative or qualitative research approach alone [20].

\section{Sampling}

This study was conducted in Jidda district. It covered all adult learners, facilitators and stakeholders of the IFAEP (public sectors and public primary schools). The sample for this study was framed from 8880 adult education program participants 352 adult education facilitators, 28 public sectors, 29 public primary schools in Jidda District and 13 rural kebele and one town. Hence, three hundred one (301) adult learners, 97 facilitators(i.e. 76 formal public primary school teachers, eight development agents, eight health extension workers, five recruited adult education facilitators), five public sector officials, five public primary school directors, five kebele managers, five civil servants were the units of observation.

To make the sample a true representative, both probability and non-probability sampling methods were employed. Therefore, the researcher applied a multi-stage sampling method to draw samples. The researcher believed that mixing those methods reduced bias and enabled them to find true representatives. According to [21], the multi-stage sampling method is applicable if the population is dispersed over a large geographical area. The researchers preferred this method because each kebele's adult education learning centers were many and standing apart in each kebele. Moreover, to determine the sample size, the researcher applied the formula used by [22]). The formula applied by those scholars is:

$$
\mathrm{n}=\frac{x 2 * N * P *(1-P)}{M E 2 *(N-1)+X 2 * P *(1-P)}
$$

Where, $\mathrm{n}=$ sample size, $\mathrm{X}^{2}=$ table value of chi-square at 1 degree of freedom at the desired confidence level, ME $=$ Margin error (squared), $\mathrm{N}=$ Total population and $\mathrm{P}=$ the assumed population proportion. Thus, by using this formula, the researcher determined the sample size at $95 \%$ $(0.05)$ confidence level with $5 \%(0.05)$ margin error and the assumed population proportion of $50 \%(0.5)$. The table value of chi-square for 1 degree of freedom at the 0.05 confidence level was 3.84 (1.96 x 1.96). Therefore, the sample size was 301 adult learners and 97 adult education facilitators for a quantitative study.

For the qualitative study, participants were selected using simple random sampling from the self-nominated participants. For the qualitative research, [23] suggested: "sample size from 5 to 25 individuals, all of whom have had direct experience with the phenomenon being studied" (p. 273). Following the recommendation of [23], a total of 20 district office officials and focal persons from the key sectors were selected for focused group discussion.

\section{Data Gathering Tools}

The closed and open-ended questionnaire was used to collect quantitative data from adult learners and facilitators. Thirty-seven questionnaire items encompassing three themes motivation, interest, commitment, and expectation were developed from the literature. A pilot was conducted in non-case study school to ensure the reliability of the items. Internal consistency of the questionnaire was found to be reliable at Cronbach alpha $0.923,0.832,0.863$, and 0.813 for motivation, interest, commitment, and expectation, respectively. These scales show that the items had good internal consistencies in measuring the same concepts.

In addition, a focus group discussion was employed for selected district office officials and focal persons from the key sectors (education, health, rural development and agriculture, civil service and good governance and women and children affairs), school directors and kebele managers. Documents such as adult literacy policy documents implementation manuals, district level and sectoral plan on adult literacy, and implementation status reports were also used.

\section{Data Analysis}

Descriptive statistics (frequency, percentage, mean and standard deviation), document analysis, and multiple regressions were used to analyse data. Test of proportion was also employed. After proper analysis, the analysis results were interpreted and presented in tables, graphs and percent. Additionally, the qualitative analysis results were supplemented thorough explanations and descriptions in the form of text.

To explain factors those determining adult learners' program attendance per week, the following multiple regression model was employed to predict the level of attendance per week for adult learners based on their age, sex, family size, appropriateness of program schedule or time, socio-economic status, marital status, current main occupation, satisfaction on the instructional methodologies used by their facilitators and adequacy of learning center resources or facilities.

$$
\begin{gathered}
\mathrm{ALP}=\beta_{0}+\beta_{1} \mathrm{Ag}+\beta_{2} \mathrm{~S}+\beta_{3} \mathrm{MS}+\beta_{4} \mathrm{FS}+\beta_{5} \mathrm{O}+\beta_{6} \mathrm{SOS} \\
+\beta_{7} \mathrm{AR}+\mathrm{B}_{8} \mathrm{SIM}+\beta_{9} \text { APS }+\varepsilon
\end{gathered}
$$

Where, $\quad \beta 0=$ constant, $\quad \beta 1, \quad \beta 2 \ldots \quad \beta 9=$ regression coefficients of the nearby variables and $\varepsilon=$ error term assumed to be normally distributed and $\mathrm{Ag}, \mathrm{S}, \mathrm{MS}$, 
FS ,O ,SOS ,AR ,SIM and APS stand for age, sex, marital status, family size, occupation, socio-economic status, adequacy of learning center resources, satisfaction on the instructional methodologies used by their facilitators and appropriateness of program schedule respectively. All those variables were coded, and all categorical variables were transformed to dummies for better regression analysis and comparisons.

\section{Ethical approval}

Ethical approval for this study was obtained from the Oromia Education Bureau in Ethiopia. Informed consent was also obtained from all the participants who took part in the study. Participation in the study was voluntary, and confidentiality maintained at all time.

\section{Results and Discussion}

In investigating the implementation status of Integrated Functional Adult Education Program in Jidda district, this research was limited to only three factors, namely (a) adult learners' participation, (b) facilitators' selection and their motivation and (c) stakeholders' collaboration.

\section{Adult learners' participation}

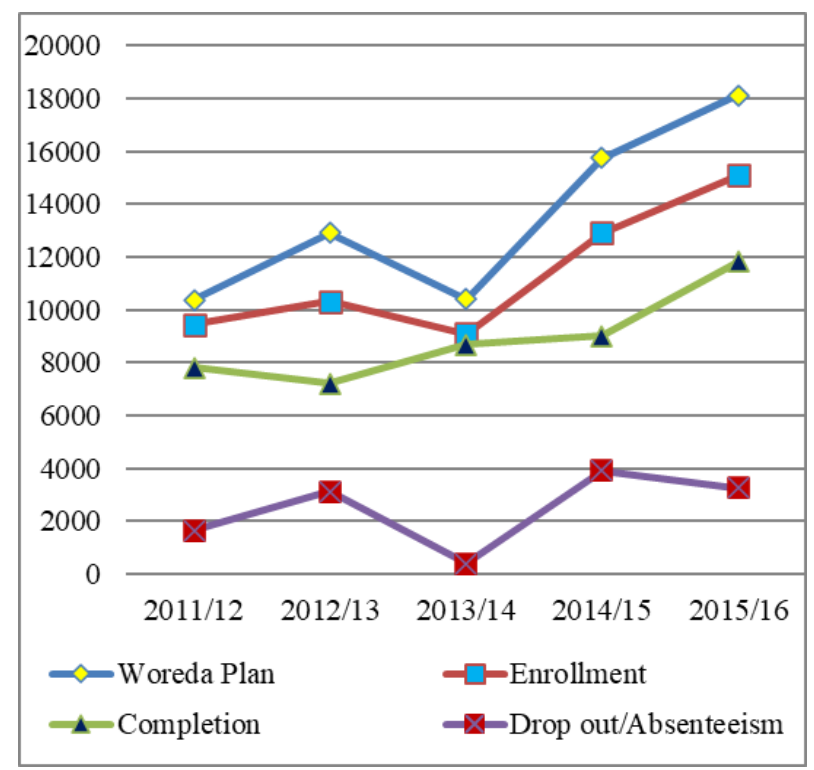

Source: Compiled from Jidda Education Office Annual Statistics and Reports [24]

Figure 1. Adult Learners' Participation Trend in Jidda District

Figure 1 shows the results concerning enrollment and completion of adults in Jidda district starting from 2011/12[24]. Accordingly, the district planned to enrol
10,378 adults in 2011/12. Out of these, 9461(5964 male and 3497 female) or $91.16 \%$ of adults were registered for the program. The data show that it was since 2012/13 when the district achieved the lowest adult learners' enrollment (i.e. $79.96 \%$ ) compared to plan and other years' achievements. Overall, the document review result indicates that there were increments in adult learners' enrolments over years though the district did not achieve the plan. However, except by the year of 2013/14 when the completion was about $95.47 \%$, the completion trend was lowered by the year of 2012/13(i.e. approximately $69.78 \%$ ) and $2014 / 15$ (i.e. about $69.76 \%$ ) when compared to the completion rate by $2011 / 12$ which was $82.54 \%$.

As can be seen from Figure 1 that the difference in enrollment and completion clearly indicated that adult learners drop out. It was only since 2013/14 when the drop out was $413(4.53 \%)$. The drop out of adults was greater than thirty percent since 2012/13 and 2014/15. Though the program delivery schedule was not finalised; about 3276(21.7\%) adult learners discontinued the program attendance until April 2016.

To cross check the secondary data on adult learners' enrollment in the study area, the sample adult learners were asked about the participation of illiterate adults in their locality (living environment). Thus, 163(55.6\%) adult learners replied that of the entire illiterate adults in their locality, only half and less than half of them were participating in program delivery at their learning center. Hence, there was statistically significant difference $\left(\mathrm{Z}_{\mathrm{cal}}=2.71, \mathrm{Z} \alpha / 2>1.96\right)$ between the actual respondents who replied as most (all) of them and half (less than) of them were participating.

Table 1. Adult Learners' Perception of Participation of Other Adult Learners

\begin{tabular}{|c|c|c|c|}
\hline \multirow[b]{2}{*}{ Response } & \multicolumn{2}{|c|}{ About Other Adults Participation } & \multirow[b]{2}{*}{ Total } \\
\hline & $\begin{array}{c}\text { All or Most of } \\
\text { them }\end{array}$ & $\begin{array}{c}\text { Half and less than } \\
\text { half of them }\end{array}$ & \\
\hline Count & 130 & 163 & 293 \\
\hline$\%$ of Total & $44.4 \%$ & $55.6 \%$ & $100 \%$ \\
\hline
\end{tabular}

The researcher raised two questions for adult education facilitators about adult learners' enrollment and their completion in their locality. Regarding enrollment, from the 92 sample facilitators, the majority (91.3\%) indicated that majority of the illiterate adults in their kebele were not participating (joining) in the integrated functional adult education program $\left(\mathrm{Z}_{\mathrm{cal}}=6.15, \quad \mathrm{Z} \alpha / 2 \quad>1.96\right)$. Similarly, as it is depicted by table 2 below, most of (93.5\%) respondent facilitators replied that majority of the adults in their kebele who voluntarily joined the program did not complete the settled program cycle or year $\left(\mathrm{Z}_{\mathrm{cal}}=6.55, \mathrm{Z} \alpha / 2>1.96\right)$. 
Table 2. Facilitators Perception of Learners' Participation

\begin{tabular}{|c|c|c|c|c|c|}
\hline \multirow{2}{*}{ No } & \multirow{2}{*}{ Questions } & & \multicolumn{3}{|c|}{ Response } \\
\hline & & & No & Yes & Total \\
\hline \multirow[b]{2}{*}{1} & \multirow{2}{*}{$\begin{array}{l}\text { Do you think that majority of the illiterate adults in your kebele are voluntarily participating } \\
\text { (joining) in the integrated functional adult education program? }\end{array}$} & Count & 84 & 8 & 92 \\
\hline & & $\begin{array}{l}\text { \% of } \\
\text { Total }\end{array}$ & $91.3 \%$ & $8.7 \%$ & $100 \%$ \\
\hline \multirow[b]{2}{*}{2} & \multirow{2}{*}{$\begin{array}{l}\text { Do you think that majority of the adults in your kebele who voluntarily joined the program } \\
\text { complete the settled program cycle? }\end{array}$} & Count & 86 & 6 & 92 \\
\hline & & $\begin{array}{l}\% \text { of } \\
\text { Total }\end{array}$ & $93.5 \%$ & $6.5 \%$ & $100 \%$ \\
\hline
\end{tabular}

The other question to adult education facilitators was about adult learners' continuous attendance of the instructional process they deliver at learning centers. Hence, as it is disclosed in table 3 , the majority $\left(Z_{\text {cal }}=5.763, Z \alpha / 2>1.96\right)$ of the 92 respondents pointed out that adult learners at their facilitation center did not continuously attend the instructional process they deliver.

Table 3. Facilitators' Perception of Adult Learners' Program Attendance

\begin{tabular}{|c|c|c|c|c|}
\hline \multirow{2}{*}{ Item } & & \multicolumn{2}{|c|}{ Response } & \multirow{2}{*}{ Total } \\
\hline & & No & Yes & \\
\hline \multirow{2}{*}{$\begin{array}{l}\text { Do you think that those } \\
\text { adults in your learning } \\
\text { center continuously attend } \\
\text { the instructional process } \\
\text { you deliver? }\end{array}$} & Count & 82 & 10 & 92 \\
\hline & $\begin{array}{l}\% \text { of } \\
\text { Total }\end{array}$ & $\begin{array}{c}89.1 \\
\%\end{array}$ & $\begin{array}{c}10.9 \\
\%\end{array}$ & $100 \%$ \\
\hline
\end{tabular}

The sample adult learners were requested to state the number of days and duration in hours they spend per week attending IFAE program delivery at their learning center. It was expected that adult learners had to attend the program for three days and 9 hours per week. Accordingly, as displayed in table 4 , results indicated that there was a statistically significant difference $\left(\mathrm{Z}_{\mathrm{cal}}=6.20, \mathrm{Z} \alpha / 2>1.96\right)$ between respondents who attended the program for less than three days and nine hours per week and those who attended for three or greater than three days and nine or above nine hours per week.

Table 4. Adult Learners' Program Attendance Days and Hours per Week

\begin{tabular}{|c|c|c|c|c|}
\hline \multirow[b]{2}{*}{$\begin{array}{c}\text { Attendance } \\
\text { Day Category }\end{array}$} & \multirow[b]{2}{*}{ Response } & \multicolumn{2}{|c|}{$\begin{array}{c}\begin{array}{c}\text { Attendance Hour } \\
\text { (per week) }\end{array} \\
\end{array}$} & \multirow[b]{2}{*}{ Total } \\
\hline & & $\begin{array}{c}\text { Less } \\
\text { than nine } \\
\text { hours per } \\
\text { week }\end{array}$ & $\begin{array}{c}\text { Nine } \\
\text { hours or } \\
\text { more per } \\
\text { week } \\
\end{array}$ & \\
\hline \multirow{2}{*}{$\begin{array}{l}\text { Less than three } \\
\text { days per week }\end{array}$} & Count & 134 & 13 & 147 \\
\hline & $\%$ of Total & $45.7 \%$ & $4.4 \%$ & $50.2 \%$ \\
\hline \multirow{2}{*}{$\begin{array}{c}\text { Three and more } \\
\text { than three days } \\
\text { per week }\end{array}$} & Count & 83 & 63 & 146 \\
\hline & $\%$ of Total & $28.3 \%$ & $21.5 \%$ & $49.8 \%$ \\
\hline \multirow{2}{*}{ Total } & Count & 217 & 76 & 293 \\
\hline & $\%$ of total & $74.1 \%$ & $25.9 \%$ & $100.0 \%$ \\
\hline
\end{tabular}

The other item the researchers posed for adult learners was about the time they attend the program delivery. Accordingly, $63.5 \%$ of the respondents attended the instructional process on holidays and during their day off. At the same time, $36.5 \%$ of adult learners attended the program on weekends and arbitrarily. Hence, majority or $63.5 \%\left(\mathrm{Z}_{\mathrm{cal}}=3.298, \mathrm{Z} \alpha / 2>1.96\right)$ of the 293 respondents attended the instructional process holidays and the day off.

\section{Facilitators' Selection and Motivation}

The researcher reviewed the annual report of Jidda district education office $(2015 / 16)$ that primary school teachers, health extension workers, development agents and permanently recruited individuals were participating in adult education facilitation consistently with what was explained in the framework. The report shows that about 26 facilitators were permanently employed for the program delivery almost two facilitators per kebele ${ }^{1}$. Overall, Table 5 below presents the results concerning facilitators' participation. As it can be observed from the table, the number of facilitators engaged in adult education facilitation increased over the years.

Table 5. Facilitators' Participation in IFAEP Facilitation

\begin{tabular}{cccc}
\hline \multirow{2}{*}{ Years } & \multicolumn{3}{c}{ Facilitators } \\
\cline { 2 - 4 } & Male & Female & Total \\
\hline $2011 / 12$ & 114 & 81 & 195 \\
$2012 / 13$ & 170 & 151 & 321 \\
$2013 / 14$ & 182 & 138 & 320 \\
$2014 / 15$ & 192 & 140 & 332 \\
$2015 / 16$ & 186 & 166 & 352 \\
\hline
\end{tabular}

Source: Compiled from Jidda District Education Office Reports

Table 6 below presents about the current main job of the respondents and their facilitation training. Accordingly, $73(79.34 \%)$ of the sample facilitators were formal school teachers, $7(7.6 \%)$ were development agents, 7(7.6\%) were health extension workers, and 5(5.4\%) were other recruited facilitators. The data showed that majority or $92.4 \%\left(\mathrm{Z}_{\mathrm{cal}}=6.351, \mathrm{Z} \alpha / 2>1.96\right)$ of the 92 facilitators had no training on adult education facilitation.

1 The smallest administrative unit similar to a ward in Ethiopia 
Though it was difficult to directly measure their motivation level [25] the researchers described facilitators' motivation through the commitment they had on their facilitation process, their interest and their expectations observed during adult education program delivery. Importantly, the assessment began by administering questionnaire for the facilitators whether they were facilitating adult education on their willingness (i.e. voluntarily) or not. Hence, while $51.1 \%$ facilitated unwillingly, the rest $48.9 \%$ taught willingly. Thus, the $Z$-test of the proportion $\left(Z_{\text {cal }}=0.149, Z \alpha / 2<1.96\right)$ indicates that $51.1 \%$ is not statistically greater than $50 \%$ and hence almost half or $51.1 \%$ of the facilitators were not willing to teach adults.

In addition to their willingness, the facilitators were also asked five questions defining their interest towards adult education facilitation. Table 7 depicts their response to the corresponding items. As indicated, about $51.1 \%$ of the facilitators expressed their disagreement on the first item. The Z- test of the proportion result $\left(\mathrm{Z}_{\mathrm{cal}}=2.921\right.$, $Z \alpha / 2>1.96)$ showed that there was statistically significant difference between the actual respondents for whom the facilitation was interesting (33.7\%) and not interesting profession $(51.1 \%)$.

The evidence also shows that majority or $72.8 \%$ $\left(Z_{\text {cal }}=3.176, Z \alpha / 2>1.96\right)$ of the 92 sample facilitators do not want to continue with adult education program facilitation. From the same table, $56.5 \%$ of the respondents stated that they did not think that they were the agent who ensures the functionality of adult learning though this figure did not constitute majority $\left(\mathrm{Z}_{\mathrm{cal}}=0.884\right.$, $Z \alpha / 2<1.96)$. However, there was statistically significant difference $\left(Z_{\text {cal }}=3.416, Z \alpha / 2>1.96\right)$ between the actual (92) sample respondents who replied as agree and disagree to this item.

Similarly, with respect to adult education facilitation satisfaction, the data from table 7 clearly showed that majority $\left(\mathrm{Z}_{\mathrm{cal}}=5.019, \mathrm{Z} \alpha / 2>1.96\right)$ of the 92 sample respondents were not satisfied with their facilitation. After all, facilitators were asked about their interest in getting training on adult education facilitation. Hence, there was no statistically significant difference $\left(\mathrm{Z}_{\mathrm{cal}}=1.183, \mathrm{Z} \alpha / 2\right.$ $<1.96$ ) between the actual respondents who replied as they needed and did not need long term training to be andragogically equipped.

Table 6. Facilitation Training and Current Main Occupation of Facilitators

\begin{tabular}{ccccccc}
\hline \multirow{2}{*}{$\begin{array}{c}\text { Facilitation } \\
\text { Training }\end{array}$} & Response & \multicolumn{5}{c}{ Current Job of Respondents } \\
\cline { 2 - 6 } & $\begin{array}{c}\text { Formal School } \\
\text { Teacher }\end{array}$ & $\begin{array}{c}\text { Development } \\
\text { Agent }\end{array}$ & $\begin{array}{c}\text { Health } \\
\text { Extension } \\
\text { Worker }\end{array}$ & $\begin{array}{c}\text { Recruited } \\
\text { Facilitator }\end{array}$ & Total \\
\hline \multirow{2}{*}{ No } & Count & 70 & 7 & 7 & 1 & 85 \\
\cline { 2 - 6 } & \% of Total & $76.1 \%$ & $7.6 \%$ & $7.6 \%$ & $1.1 \%$ & $92.4 \%$ \\
\hline \multirow{2}{*}{ Yes } & Count & 3 & 0 & 0 & 4 & 7 \\
\hline \multirow{2}{*}{ Total } & \% of Total & $3.3 \%$ & $0.0 \%$ & $0.0 \%$ & $4.3 \%$ & $7.6 \%$ \\
\cline { 2 - 7 } & Count & 73 & 7 & 7 & 5 & 92 \\
\hline
\end{tabular}

Table 7. Facilitators' Interest on Adult Education Facilitation

\begin{tabular}{|c|c|c|c|c|c|c|c|}
\hline \multirow{3}{*}{ No } & \multirow{3}{*}{ Items } & \multicolumn{6}{|c|}{ Alternative Responses } \\
\hline & & \multicolumn{2}{|c|}{ Disagree } & \multicolumn{2}{|c|}{ No comment } & \multicolumn{2}{|c|}{ Agree } \\
\hline & & $\mathbf{F}$ & $\%$ & $\mathbf{F}$ & $\%$ & $\mathbf{F}$ & $\%$ \\
\hline 1 & Adult education facilitation is interesting profession for me. & 47 & $51.1 \%$ & 14 & $15.2 \%$ & 31 & $33.7 \%$ \\
\hline 2 & I plan to continue in adult education facilitation Profession. & 67 & $72.8 \%$ & 9 & $9.8 \%$ & 16 & $17.4 \%$ \\
\hline 3 & $\begin{array}{l}\text { I teach because I think that I am the agent who ensures the functionality of adult } \\
\text { learning. }\end{array}$ & 52 & $56.5 \%$ & 11 & $12 \%$ & 29 & $31.5 \%$ \\
\hline 4 & I am satisfied with my facilitation. & 63 & $68.5 \%$ & 15 & $16.3 \%$ & 14 & $15.2 \%$ \\
\hline 5 & I need long term training to be andragogically equipped. & 39 & $42.4 \%$ & 6 & $6.5 \%$ & 47 & $51.1 \%$ \\
\hline
\end{tabular}


Table 8. Facilitators' commitment to facilitation

\begin{tabular}{|c|c|c|c|c|c|c|c|}
\hline \multirow{3}{*}{ No } & \multirow{3}{*}{ Items } & \multicolumn{6}{|c|}{ Alternative Responses } \\
\hline & & \multicolumn{2}{|c|}{ Disagree } & \multicolumn{2}{|c|}{ No comment } & \multicolumn{2}{|c|}{ Agree } \\
\hline & & $\mathbf{F}$ & $\%$ & $\mathbf{F}$ & $\%$ & $\mathbf{F}$ & $\%$ \\
\hline 1 & $\begin{array}{l}\text { I have formed strong team } \\
\text { sprit with my colleagues. }\end{array}$ & 40 & $43.48 \%$ & 21 & $22.83 \%$ & 31 & $33.69 \%$ \\
\hline 2 & $\begin{array}{c}\text { I teach adults because I am } \\
\text { responsible. }\end{array}$ & 54 & $58.67 \%$ & 9 & $9.78 \%$ & 29 & $31.5 \%$ \\
\hline 3 & $\begin{array}{l}\text { I communicate about } \\
\text { challenges I encountered in } \\
\text { my facilitation early. }\end{array}$ & 45 & $48.9 \%$ & 13 & $14.1 \%$ & 34 & $37 \%$ \\
\hline 4 & $\begin{array}{c}\text { I never missed my teaching } \\
\text { session of my learners without } \\
\text { replacing. }\end{array}$ & 63 & $68.47 \%$ & 14 & $15.22 \%$ & 15 & $15.31 \%$ \\
\hline
\end{tabular}

The questionnaire that was administered to the facilitators also contained four items concerning facilitators' commitment for their facilitation and table 8 below presents their reply to those statements. As ascribed in the table, $33.69 \%$ and $43.48 \%$ facilitators expressed their debate that they formed strong team spirit with their colleagues for effective facilitation of adults learning and did not formed respectively. However, there was no statistically significant difference $\left(Z_{\text {cal }}=1.364, Z \alpha / 2<1.96\right)$ between facilitators who replied as they formed and did not form strong team sprit with their colleagues. Similarly, $58.67 \%$ of 92 sample respondents expressed their disagreement regarding their facilitation responsibility though the figure did not constitute the majority $\left(\mathrm{Z}_{\mathrm{cal}}=1.181, \mathrm{Z} \alpha / 2<1.96\right)$. However, there was statistically significant difference between actual sample respondents who thought that they were responsible for facilitation and those who thought that they were not responsible $\left(Z_{\mathrm{cal}}=3.703, \mathrm{Z} \alpha / 2>1.96\right)$. For the third statement about communication, the test showed that there was no statistically significant difference $\left(Z_{\text {cal }}=1.630, Z \alpha / 2<1.96\right)$ between the actual respondents who communicated and did not communicate early about the problem they encountered during their facilitation. For the last item in table 8 , most (i.e. $68.47 \%, \mathrm{Z}_{\mathrm{cal}}=2.549, \mathrm{Z} \alpha / 2>1.96$ ) of 92 respondents avowed that they missed their facilitation sessions without replacing.

To crosscheck about the facilitators' commitment towards their facilitation, the researcher administered schedule for adult learners. Thus, the first question asked whether all of their facilitators (teachers, development agents, health extension workers and other recruited facilitators) form strong team spirit to jointly facilitate their learning or not. From the 293 sample respondents, majority or $60.75 \%(\mathrm{Zcal}=2.617, \mathrm{Z} \alpha / 2>1.96)$ replied that their facilitators were not working together and the rest $39.25 \%$ agreed that facilitators were working jointly.

The other question administered to sample adult learners was about their perception towards their facilitators' commitment. Accordingly, Figure 2 shows their response.

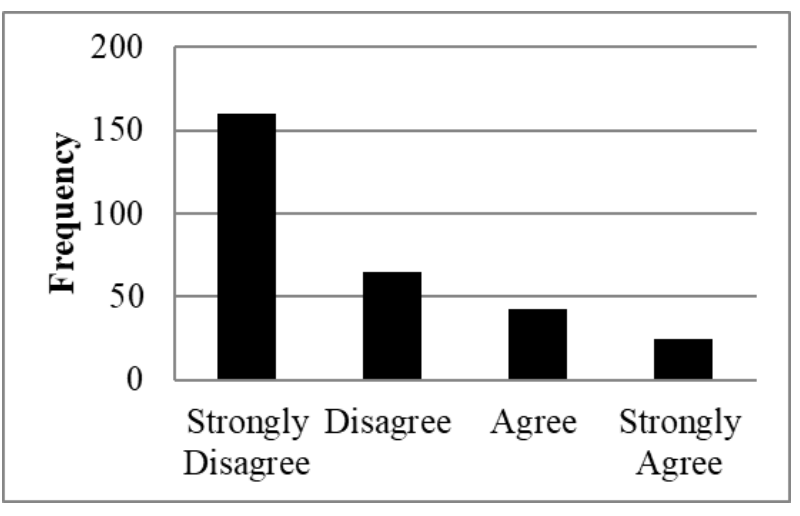

Figure 2. Adult Learners Perception about Facilitators' Commitment

As it can be seen from figure 2, about $76.79 \%$ of 293 adult learners expressed their disagreement with respect to their facilitators' commitment. Thus, most of those respondents $\left(Z_{\text {cal }}=6.731, Z \alpha / 2>1.96\right)$ replied that their facilitators were not committed. Most similarly with preceding question about their commitment, majority or $77.47 \%\left(Z_{\mathrm{cal}}=6.916, \mathrm{Z} \alpha / 2>1.96\right)$ of 293 adult learners complained that their facilitators were not reaching to adult learning center on time.

The other question was about facilitators' expectations regarding IFAE program implementation. Table 9 displays the controversies with respect to their expectation. For the first item, though the figure did not imply the majority, about $58.7 \%$ of 92 facilitators expected that they would be rewarded when their facilitation performance was well. Thus, there was statistically significant difference $\left(Z_{\mathrm{cal}}=3.693, \mathrm{Z} \alpha / 2>1.96\right)$ between respondents who expressed their agreement and disagreement regarding rewarding system expectation.

The same table also shows that of the 92 respondents, $35.87 \%$ and $54.35 \%$ of them expected that everybody took and did not take the facilitation responsibility with them for their facilitation respectively. Hence, there was a significant difference $\left(\mathrm{Z}_{\mathrm{cal}}=2.519, \mathrm{Z} \alpha / 2>1.96\right)$ among those respondents. However, for the item dealing with fair treatment, the evidence showed that there was no statistically significant difference $\left(Z_{\mathrm{cal}}=0.903, \mathrm{Z} \alpha / 2<1.96\right)$ 
between respondents who replied that they would be treated fairly and would not be treated fairly with other facilitators. The last item dealt about recognition from program coordinators or managers. Consequently, the data showed that there was statistically significant difference between the actual respondents who expected that they would get and would not get recognition from their coordinators $\left(\mathrm{Z}_{\mathrm{cal}}=3.273, \mathrm{Z} \alpha / 2>1.96\right)$.

\section{IFAEP Stakeholder Collaboration}

The sample facilitators who were asked a question about the stakeholders of the IFAE program in their locality were closely working together for its effective implementation. Majority or $87 \% \quad(\mathrm{Zcal}=5.402$, $Z \alpha / 2>1.96)$ of the 92 facilitators replied that the stakeholders were not working together. Only $13 \%$ of respondents indicated that the stakeholders were jointly working together for effective program implementation.

Similarly, the facilitators were asked to express their opinion on some issues about collaboration. As summarised on Figure 3, of the 92 sample respondents, most $(72.83 \%)$ of the facilitators stated that there was weak stakeholder collaboration on preparing a comprehensive plan on IFAEP (Zcal=3.181, $\mathrm{Z} \alpha / 2>1.96$ ). The same figure shows that, the majority or $70.65 \%$ ( $\mathrm{Zcal}=2.862, \mathrm{Z} \alpha / 2>1.96)$ of the 92 respondents pointed out that collaboration on communicating and working with the community to solve problems facilitators' face during facilitation was also weak.

The other stakeholder collaboration problem was observed with respect to the provision of necessary resources. In this regard, 73.91\% (Zcal=5.964, $\mathrm{Z} \alpha / 2>1.96$ ) of the 92 sample respondents replied that cooperation on resource provision at adults learning was weak. With respect to identifying and registering adults in accordance to their literacy level, $54.35 \%$ respondents evaluated the stakeholder collaboration as weak and $26.09 \%$ as moderate. Hence, the difference was statistically significant $\quad(\mathrm{Zcal}=6.976, \quad \mathrm{Z} \alpha / 2 \quad>1.96) . \quad$ However, concerning collaboration on adult learner mobilisation, the test of proportion of difference between respondents who evaluated as weak $(40.22 \%)$ and as moderate $(35.87 \%)$ shows that there was no statistically significant difference ( $\mathrm{Ccal}=0.608, \mathrm{Z} \alpha / 2<1.96$ ). Likely with the previous item, the difference was statistically insignificant $(\mathrm{z}=1.481)$ for the sample respondents responded either moderate $(40.22 \%)$ or weak $(51.1 \%)$ for collaboration on awareness creation for community.

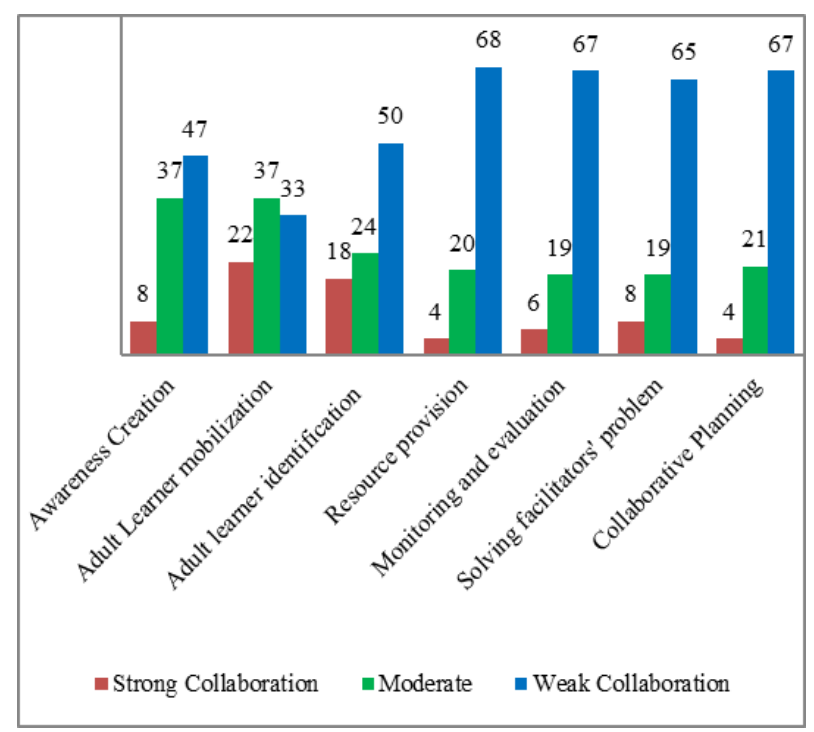

Figure 3. Level of Stakeholder Collaboration

Table 9. Facilitators' Expectation about IFAE Program Implementation

\begin{tabular}{|c|c|c|c|c|c|c|c|}
\hline \multirow{3}{*}{ No } & \multirow{3}{*}{ Items } & \multicolumn{6}{|c|}{ Alternative Responses } \\
\hline & & \multicolumn{2}{|c|}{ Disagree } & \multicolumn{2}{|c|}{ No comment } & \multicolumn{2}{|c|}{ Agree } \\
\hline & & $\mathbf{F}$ & $\%$ & $\mathbf{F}$ & $\%$ & $\mathbf{F}$ & $\%$ \\
\hline 1 & $\begin{array}{c}\text { I will get reward when I perform facilitation } \\
\text { well. }\end{array}$ & 30 & $31.6 \%$ & 8 & $8.7 \%$ & 54 & $58.7 \%$ \\
\hline 2 & $\begin{array}{l}\text { Everybody will take the facilitation } \\
\text { responsibility with me for facilitation. }\end{array}$ & 50 & $54.35 \%$ & 9 & $9.78 \%$ & 33 & $35.87 \%$ \\
\hline 3 & $\begin{array}{l}\text { I will be treated fairly and equally with other } \\
\text { facilitators. }\end{array}$ & 40 & $43.48 \%$ & 18 & $19.57 \%$ & 34 & $36.95 \%$ \\
\hline 4 & $\begin{array}{l}\text { I will get recognition from my managers or } \\
\text { facilitation coordinators when I do well as a } \\
\text { facilitator. }\end{array}$ & 51 & $55.44 \%$ & 12 & $13.04 \%$ & 29 & $31.52 \%$ \\
\hline
\end{tabular}




\section{Implementation Challenges}

The implementation of IFAEP was not free from irregularities and challenges in Jidda district. Based on results of the focus group discussions, the challenges were organised under five thematic areas (below).

\section{Challenges in Program Conceptualization and Popularization}

Program conceptualisation and popularisation is one of compulsory strategic directions for the effective implementation of IFAE program as endorsed in the national adult education strategy [14]. This point was a landmark for the researcher to begin an investigation through focus group discussion on how the integrated functional adult literacy program was conceptualised, whether the program was really integrated and functional. Consequently, the discussants from both groups defined the program as it is education system for the improvement of livelihood of adults. The discussants further elaborated that the program goes beyond lettering as explained in the framework of [26]. However, the discussants summarised that all of the stakeholders especially the target group were not well aware of this program. The discussants from group one (i.e. district officials and experts) debated that even the key program implementers had no similar consensus and understanding on the program.

By linking to program conceptualisation, the researcher raised agenda for the group discussants to assess the challenges of the discrepancies concerning adult learner participation. Accordingly, the discussants elaborated program popularisation as a critical problem. It was further explained that the program was not common concern and it missed attention. Foremost, the program lacked proper and consecutive orientation. Results of the focus group discussions implied that only teachers and education sector experts know about the science of the program. The commonly known issue was that the program was designed to be implemented by three key sectors such as education, health and agricultural and rural development sector. From group one, one of the discussants raised that:

Integrated functional adult education program did not get district officials' attention. Except for the three key sectors' officials, I don't think officials of other sectors have a detailed understanding about this program. Even, I never heard in any report or evaluative meeting about resource and budget the District provided for the implementation of this program. I personally believe that without district officials' focus and necessary resourcing, the program cannot be implemented.

The other discussant from group one added that:

The implementation of integrated functional adult education program was not monitored and evaluated; even the effectiveness level was not known; facilitators were teaching only theory and spelling. I think the integratedness and functionality of the program was more of oral and on paper plan only.

The discussion with group two (i.e. school directors and kebele managers) confirmed the above statements that though the contents in the books for adult learners were comprehensive and integrated to the daily life of adults, it was not practiced as intended. They further justified that the program delivery was traditional which means teaching only spelling. They added that it was not clearly known whether the program reached the target group. Even adults of different levels learn together and they showed that there was no legal framework for the graduated learners. Directors announced that rather than 'wagga lakkaa'u' literary translated as 'year counting', they did not evaluate with the settled standard for each cycle. As to them everybody was satisfied only with the number of adults registered at the beginning. No one closely knew how the program was operated. They were only facilitators who reported how they were facilitating.

To sum up, the focus group discussion disclosed that the program implementation lacked awareness, orientation and trainings, especially for facilitators, common consensus and understanding, giving priority and attention like other development activities. Absence of legal frameworks like books and other guiding principle for the graduated learners was also a concern reflected from the discussion. From the discussion, it was also observed that school directors have a better understanding than other discussants do. From the review of the implementation guideline, the researcher analysed that the expected competences or profile of adult learners were not specified.

\section{Challenges Related to the Organization of the Program and Adult Learning Centers}

The other serious problem widely stated by the focus group discussants was related to the organisation of adult learning centers. The discussants strongly affirmed that some centers were non-existent except in name. The discussant further justified that some facilitators communicate with the community somewhere in places like 'Idir', 'Iqub' and other ceremonial places. Even the organised centers were not resourced and were not suitable for adult learning. The discussants also reflected that many learning centres were not attractive; the seats were not comfortable, and sometimes the centers were not permanent.

Most openly the school directors stated that teachers reach at adult learning centers simply because they would be evaluated. Few of them also complained that the issue of adult facilitation was included only in teachers' performance what was locally known by teachers as 'efficiency' which means that other facilitators like development agents and health extension workers were not evaluated in such a way. The discussants concluded 
that there was inconsistent process of program delivery.

The other observed problem was about non- existence and non- functionality of both board and technical committees of adult education at district and kebele level. Some of the discussants explained that the committees were organised only on paper. Even some of the members do not know that they are members. There were no roles and duties of committee members played yet. The discussants elaborated that the responsible entities like district and kebele level adult education board committees and the program technical committees at all levels were not coordinating.

The identification of adults on their literacy level base was other series problem recognised by the discussants. This means all adults were not identified and registered properly. One of the school directors boldly explained that there was no mother document which lists out all adults in accordance with their literacy level as per explained in the guidelines. The schools rather host only some adults by door to door registration locally known as 'kakasi'.

\section{Program Stakeholder Collaboration Challenges}

The focus group discussions also contained the issue of collaboration among stakeholders as a talking point or agenda. Thus, the discussion assured that the program was left to only district education sector particularly for schools and teachers. They further elaborated that there was no communication among the key stakeholders. One of the discussants stated that:

I always observe that it was only Jidda district education sector that was responsible for teaching adults. I personally experienced that collaboration was somehow seen during adult learner registration. I feel that no one can enforce health extension workers and development agents. I think teachers never had common discussion and reached on consensus with those facilitators.

It was summarised by the discussant that the stakeholders were not willing to collaborate. One of the discussants mentioned the following:

There was underestimation among facilitators. Even there were no frequent and adequate orientations on adult education program. What was always questionable was over reporting without reaching the target group. Key sectors repeatedly report what education sector report.

From the focus group discussion, it was conceptualised that there was no stakeholder collaboration and even very weak where there was attempt of collaborating. The program implementation also lacked similar enforcement from the key sectors. The stakeholders had no common objective on adult literacy. Even those key sectors had no their own plan on adult literacy. There was no term of reference among the stakeholders. Hence, the provision of adult education was not commonly planned, implemented and monitored. It was also indicated as there were lack of communication among the stakeholders; lack of proper orientation and discussion; false reporting and unwillingness of stakeholders for collaboration.

\section{Problems Related to Adult Learners}

The other irregularity was related to the perception of adult learners towards the program. The discussants, especially school directors, reported that adult learners repeatedly had an appointment on which they were not present. The discussants further complained that adult learners' participation especially discontinuous attendance was due to the negative perception of adults towards their participation in the program. According to their clarification, adults had many jobs to do like teaching children; had no suitable and sufficient time to attend it; adults think that there was nothing special content of learning which means had prior knowledge on it; they think that they cannot be effective because of their age.

In order to validate those challenges that were raised by discussants, the researcher administered similar questionnaire and schedule item for facilitators and adult learners which asked about the hindering factors of adult learners' participation. Hence, some adults had no plan and interest to join the program, having personal job burden and no sufficient time to attend, and some of them also replied that they could not be effective due to their aging jotted as 'where to reach through this program'. The facilitators also listed out factors like lack of adult learners' motivation, interest and lack of awareness. Inappropriateness of program schedule (time), social and economic problems, personal job burden and learning center unsuitability were also other factors written by some of the facilitators.

\section{Facilitators Related Problems}

In addition to the mentioned challenges, the researcher employed focus group discussion with respect to challenges related to facilitators' motivation. Some of the discussants complained that most of the facilitators were not interested and motivated for adult education facilitation. They justified that only some of committed teachers were repeatedly facilitating. Those discussants charged that other facilitators were saying that they had another activity to do rather than facilitation. Some officials pointed this backward and forward problem to development agents and health extension workers.

Some of the discussants boldly raised that the facilitators became reckless thinking that they had any additional incentives. Especially, some of the school directors openly presented the why only teachers complain. They further justified that teachers perceived their facilitation as there was no change rather than 
1482 The Assessment of Integrated Functional Adult Education Program in Oromia Regional State, Ethiopia: Reflection on Practice

reaching center; as additional job burden which they thought that overlap with their formal job and there was no personal benefit. Finally, the discussion was concluded as there were clear indications for lack of facilitators' motivation.

Table 10. Regression Result for the Program Attendance Day per Week for Adult Learners

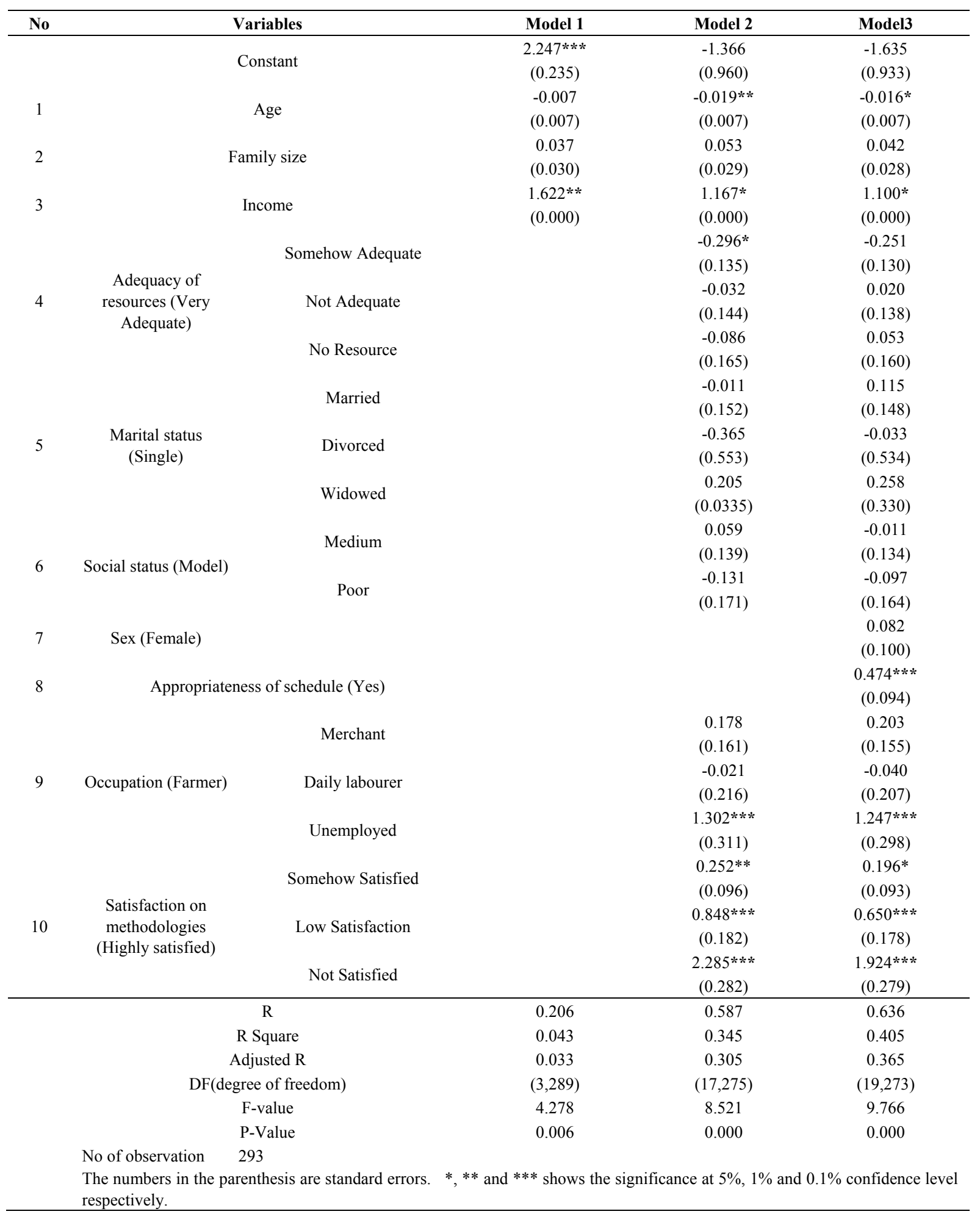




\section{Result Pertinent to the Factors that Determine Adult Learners' Participation (RQ3)}

This section discussed that factors such as age, sex, family size, appropriateness of program schedule or time, socio economic status, marital status, current main occupation, satisfaction on the instructional methodologies used by their facilitators and adequacy of learning canter resources determine the adult learners' program attendance per week. Hence, in order to explain variations in adult learners' program attendance day per week, multiple regressions analysis was conducted.

The researcher had conducted hierarchical regression analysis in order to explain statistically factors of variance on the program attendance day per week for adult learners. Table 10 discloses the potential predictor contributed to the regression models. As displayed, all the scale variables were inserted first. Subsequently, the dummies were added and finally all the dichotomies were incorporated.

Progressive addition of those variables improved the model fitness and variance of explanation (prediction) on program attendance day per week for adult learners. Therefore, the last model (model 3) had greater significant F- value (i.e. 9.776) and higher coefficient of determination $\left(\mathrm{R}^{2}=0.405\right)$. Hence, it had greater explanatory power than model 1 and model 2 . As a result, $40.5 \%$ of the total variance on the level of program attendance day per week for adult learners was explained jointly by the factors that were included in model 3 . Consequently, variables such as age, annual income, occupation, satisfaction level on methodologies and appropriateness of program schedule or time were statistically significantly contributed to the model.

As indicated in Table 10, model 3 predicted that keeping all other variables constant, the program attendance day per week for adult learners' decreases as their age increases. Thus, the coefficient for age indicates that for an increase of adult learners' age by one year, their program attendance day per week decreases by 0.016 on average when controlled for other independent variables. Hence, age and program attendance per week for adult learners has significantly negative relationship.

Assuming all other variables stable, program attendance day per week for adult learners and their annual income have a positive relationship. Thus, for increase of annual income of the adult learners by one birr (Ethiopian currency), their program attendance day per week exceeds averagely by 1.10 . Controlling for all other predictors, the level of program attendance day per week for adult learners for whom the program schedule appropriate is significantly higher when compared to those the program schedule is not appropriate.

The model predicted that there is a statistically significant difference between farmers and unemployed adult learners on adult education program attendance per week. Thus, the coefficient shows that IFAEP attendance day per week for unemployed adults is significantly higher, when compared to farmer adult learners holding all other variables fixed. However, the regression result shows that there is no statistically significant difference on program attendance day per week for merchant and daily labourer adult learners when compared with farmer adult learners.

The program attendance per week for adult learners is significantly higher for those who have no satisfaction, moderate and low level of satisfaction on instructional methodologies used by their facilitators when compared to those who are highly satisfied holding all other predictors constant. Furthermore, the result showed that predictors such as sex, family size, marital status, social status and adequacy of resources were statistically insignificantly contributed to model 3 of the multiple regressions.

\section{Conclusions}

The introduction of IFAEP is to improve all adults' livelihood, and the core principle for the program operation should be the participation of all illiterate adults in the program. However, IFAEP implementation in Jidda district is weak in these respects. This is because; firstly, the evidence shows that there are still many adults who did not join the program. Discontinuous program attendance and attending the program below the targeted program time is also other problematic concerns in the study area. Rather than teaching all level adults together, it is questionable whether the target groups are attending and graduating from the program or not. Secondly, the study pointed out that facilitators in study area lacked motivation in program facilitation. Evidence from different data sources exposed that the facilitators were not committed and interested in their facilitation. Thirdly, the stakeholder collaboration is one of the bottlenecks in the study area. Collaboration through resourcing, monitoring and evaluation, solving problems facilitators encountered and collaborative planning were weak in the study area. Therefore, the inclusion of only some portion of those target groups and delivering the program below targeted schedule with the engagement of only some stakeholders and facilitators may not contribute to expected development aspects.

On the other hand, the implementation of IFAEP with respect to adult learners' participation, facilitators' motivation and program stakeholder is inconsistent because of multiple practical challenges which are related to program popularisation and understanding, organisation of the program and adult learning centres, program stakeholder, adult learners and facilitators related problems. Effective delivery of this program had better start early from program understanding and popularisation, proper identification of adult learners and selection of committed and interested facilitators. Unless the program 
operation is collaboratively planned, resourced and monitored, it is really difficult to know whether the program is for the needy and up to the expected pace. So, effective monitoring and evaluation in program operation has its own stance to improve program implementation in Jidda district.

Adult learners are the central beneficiaries of IFAEP. This is realised if they continuously and adequately attend the program on the targeted program time. Different factors determine the variation in program attendance day per week for adult learners in the study. Adult learners' age has negative effects on their program attendance. The annual income of the adult learner has a positive effect on their program attendance. Similarly, appropriateness of the program time, adult learners' occupation and their satisfaction level on the instructional methodologies used by the facilitators explained the variation on adult learners' program attendance day per week in the study area.

For the future, similar studies with more participants from other regions on adult education program could be carried out in Ethiopian contexts and other African countries to build up a more coherent picture of the practice of adult education program evaluation. Comparative studies between different countries would also be useful. In addition, in this study, participants' level of motivation was measured in terms of their commitment to the program, although adult learning motivation could be measured through different frameworks or approaches. The use of a variety of motivation measurement is recommended in the future.

This paper is part of a publicly master thesis. It has been rearranged and prepared for the sake of knowledge dissemination.

\section{REFERENCES}

[1] Ministry of Education. "Education sector development programme V (ESDP V) 2016 - 2020". Addis Ababa, Ethiopia: Ministry of Education; 2015.

[2] Elfert M, Walker J. "The rise and fall of adult literacy. Policy Lessons from Canada". European journal for Research on the Education and Learning of Adults. 2020;11(1):109-25.

[3] Seo H, Erba J, Altschwager D, Geana M. "Evidence-based digital literacy class for older, low-income African-American adults". Journal of AppliedCommunicati on Research. 2019;47(2):130-52.

[4] Wagner DA. "Literacy and adult education: Thematic Studies". Dakar, Senegal: UNESCO; 2000.

[5] Faradova G. "Adult Education: Contribution to the Sustainable Development Goals". In: Leal Filho W, Azul AM, Brandli L, Özuyar PG, Wall T, editors. Quality Education. Cham: Springer International Publishing; 2020. p.
$1-17$.

[6] Gezahegn E. "Implementation of adult education by the Ethiopian Kale Heywet Church: Challenges and opportunities". Unpublished MA Thesis) Addis Ababa: Addis Ababa University. 2014.

[7] Abideen SNU, Nadeem F, Abideen SA. "Genetic variability and correlation studies in Brassica napus L. genotypes". International Journal of Innovation and Applied Studies. 2013;2(4):574-81

[8] Ministry of Education. "Education and training policy". Addis Ababa, Ethiopia: Ministry of Education; 1994.

[9] Ministry of Education. "Education sector development program (ESDP IV) (2010-2015)". Addis Ababa 2010.

[10] Ministry of Education. "ESDP IV Education Sector development Program, 2010-2015)". Addis Ababa 2010.

[11] Ministry of Education. "Education sector development program IV (2010/2011 2014/2015)". Addis Ababa, Ethiopia: Ministry of Education; 2010.

[12] MOFED. "Growth and Transformation Plan Annual Progress Report for F.Y.2012/13 ". Addis Ababa, Ethiopia: MOFED; 2014

[13] Education for All. "Education for all 2015 national review report: Ethiopia". Addis Ababa, Ethiopia: UNESCO; 2015.

[14] Ministry of Education. "National adult education strategy". Addis Ababa, Ethiopia: Ministry of Education; 2008.

[15] Gelana G. "An assessment of Ethiopia's progress towards attaining integrated functional adult literacy". Bahir Dar Journal of Education. 2014;14(2).

[16] Selamawit H. "An assessment of the implementation of functional adullt literacy in Merhabete woreda: best practice and lessons to be learne. Addis Ababa, Ethiopia: Addis Ababa University; 2014.

[17] UNESCO. "Teaching and learning: Achieving quality for all". Paris, France: UNESCO; 2014.

[18] UNESCO Institute for Statistics. "Adult and youth literacy, 1990-2015: Analysis of data for 41 selected countries". Quebec, Canada: UNESCO; 2012.

[19] Jidda Woreda Education Office. "Jidda Woreda ESDP V, (2015/16-2019/20)". Jidda: Oromia Education Bureau; 2016.

[20] Denscombe M. "The good research guide: for small-scale social research projects". London: McGraw-Hill Education 2014.

[21] Kothari CR. "Research methodology: Methods and techniques". New Delhi: New Age International; 2004.

[22] Krejcie RV, Morgan DW. "Determining sample size for research activities". Educational and psychological measurement. 1970; 30(3): 607-10. doi: https://doi.org/10.1 177/001316447003000308.

[23] Leedy PD, Ormrod JE. "Practical research: planning and design". Essex: Pearson Education 2015.

[24] Jidda Woreda Education Office. Jidda woreda education office annual reports (2011/12-2015/16). Jidda Woreda 
Education Office2016.

[25] Gultekin H, Erkan A. "The intrinsic and extrinsic factors for teacher motivation". Revista de cercetare si interventie sociala. 2014;47:291.
[26] Oromia Education Bureau. "The IFAEP Implementation Guideline". Addis Ababa, Ethiopia: Oromia Education Bureau; 2012. 

